\title{
ICE LOSS IN THE ABLATION AREA OF A HIMALAYAN GLACIER; STUDIES ON MIAR GLACIER, KARAKORAM MOUNTAINS, PAKISTAN
}

by

\author{
G.J. Young and J.P. Schmok*
}

(Snow and Ice Hydrology Project, Wilfrid Laurier University, Waterloo, Ontario N2L 3C5, Canada)

\section{ABSTRACT}

One of the main aims of the Snow and Ice Hydrology Project, a joint Canada-Pakistan endeavour, is to estimate ice loss in the ablation areas of glaciers in order to predict with greater confidence stream flow in the headwaters of the Indus River. To this end, Miar Glacier, located in the central Karakoram Range, north of Gilgit, was intensively studied during the summers of 1986 and 1987.

Measurements of glacier mass balance by the monitoring of accumulation and ablation at stake locations is very difficult in the Himalyan environment. It is usually almost impossible to reach elevations above the equilibrium line without major effort, and always very difficult once there to make meaningful measurements; the ablation areas are of ten heavily crevassed and/or debris-covered, and this poses difficult sampling problems.

The method used in this study was to monitor annual surface movement on a cross-profile as near as possible to the equilibrium line. The measurements, obtained in conjunction with depth soundings made on the same profile, allow the annual ice flux through the cross-profile to be calculated. If an approximately steady-state glacier is assumed, it would be expected that this flux would be roughly equivalent to the rate of ice loss below the profile.

The movements of wooden stakes drilled into the glacier were monitored throughout each of the summers and, since two of the stakes survived the intervening winter, this allowed calculation of annual movement. Distances between the crests of ogives were also surveyed, providing an independent assessment of glacier movement. Depth measurements by radio-echo sounder were successfully made in the summer of 1987, showing maximum ice depths of $550 \mathrm{~m}$. The annual ice flux through the transverse profile was estimated as $5.67 \times 10^{7} \mathrm{~m}^{3}$, which corresponds to a mean annual ice loss from the glacier surface below the profile of $8.10 \mathrm{~m}$ of ice.

\section{INTRODUCTION}

Movement and ablation studies on Miar Glacier are part of the Snow and Ice Hydrology Project, a comprehensive research effort in the Karakoram Himalaya, the prime aim of which is to elucidate the interplay between the rainfall, snow-melt, and ice-melt components of the hydrology of the Upper Indus basin. Detailed descriptions of the project, conducted on a bilateral basis between the Water and Power Development Authority (WAPDA) in Pakistan and several Canadian universities, have been given by Hewitt (1985) and Snow and Ice Hydrology Project (Hewitt, 1986, 1987).

* Present address: Department of Astronomy and Geophysics, University of British Columbia, Vancouver, British Columbia, Canada.
Measurement of glacier mass balance by monitoring accumulation and ablation over an annual, or even a summer, period at sta locations is difficult in the Himalayan environment. is usually almost impossible to reach elevations above the equilibrium line without major effort, and always very difficult once there to make meaningful measurements. The ablation areas are of ten heavily crevassed and/or debris-covered, and this poses difficult sampling problems. The method used in this study is to monitor annual surface movement on a cross-profile as near as possible to the equilibrium line. The measurements obtained, in conjunction with depth soundings made on the same profile, allow the annual ice flux through the cross-profile to be calculated (Reid and Paterson, 1973). If an approximately steady-state glacier is assumed, this flux would be expected to be roughly equivalent to the rate of ice loss below the profile. If the cross-profile is coincident with 3 equilibrium line, then the flux would also be expected to be approximately the same as the accumulation rate above the profile.

\section{THE FIELD AREA}

Miar Glacier lies within the drainage system of the Barpu River, a tributary of the Hunza River in the central Karakoram of northern Pakistan. It is approximately $28 \mathrm{~km}$ in length and has an area of $53 \mathrm{~km}^{2}$. Its equilibrium line at approximately $4100 \mathrm{~m}$ roughly coincides with the top of a steep ice fall (Fig. 1). It ranges in elevation from $2850 \mathrm{~m}$ at its snout to about $7000 \mathrm{~m}$ at the highest parts of its accumulation area (Table I). The accumulation area is mainly avalanche-fed and the ablation area is remarkably debris-free. In places there is evidence of small rockfalls on to the glacier surface but these are far smaller than the immense collections of rockfall debris found on the adjacent Sumaiyarbar and Bualtar Glaciers. Neither major medial moraines nor extensive crevasse fields are found in the ablation area below the ice fall. There is a series of very obvious wave ogives below the ice fall, and it is these features which make the ablation area of Miar Glacier accessible and almost ideal for field study (Fig. 2).

\section{METHODS AND INSTRUMENTS}

The instrument system used to sound glacier thickness is a monopulse radar similar to that described by Rose and Vickers (1974), Watts and England (1976), Clarke (1977), and Watts and Wright (1981). The system is easily carried by a group of three people and consists of a transmitter and antenna which together generate a very short-duration pulse centred at between 1 and $5 \mathrm{MHz}$, and a receiving antenna plugged into the high-impedance input of an oscilliscope. Most soundings were made at about $1 \mathrm{MHz}$ using $40 \mathrm{~m}$ antenna half-lengths, but in addition a few shallow soundings were made with shorter antennae.

The receiver is a small, portable oscilloscope Tektronix 221 , having a band width of $5 \mathrm{MHz}$, high input impedence, and $1 \mu \mathrm{s}$ per division horizontal sweep rate. This instrument 


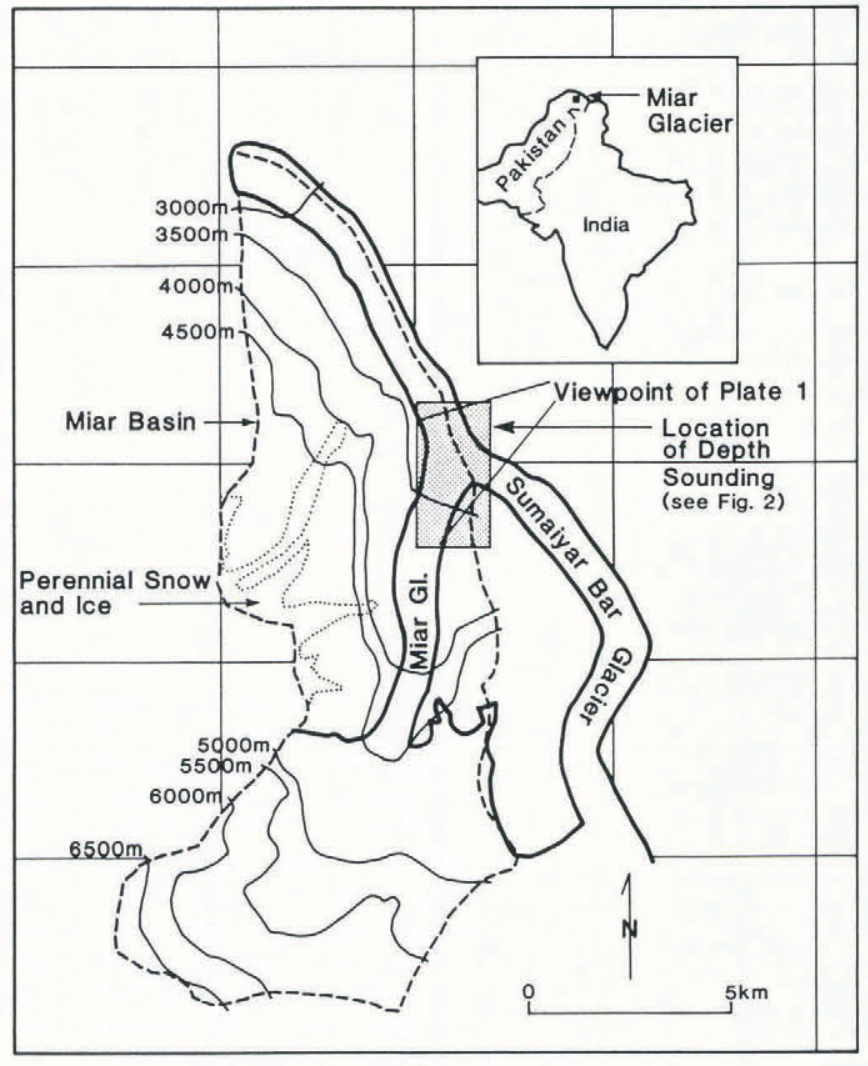

Fig. 1. Map of the Miar Glacier basin.

TABLE I. AREA-ELEVATION RELATIONSHIP WITHIN THE MIAR GLACIER BASIN

$\begin{array}{lrrrc}\text { Elevation } & \text { Total area } & \text { Rock } & \text { Glacier } & \begin{array}{c}\text { Perennial } \\ \text { snow }\end{array} \\ \text { m a.s.l. } & \mathrm{km}^{2} & \mathrm{~km}^{2} & \mathrm{~km}^{2} & \mathrm{~km}^{2} \\ & 1.89 & 0.18 & 1.71 & - \\ 3000 & 11.39 & 5.60 & 5.79 & - \\ 3500-3500 & 16.46 & 12.69 & 3.75 & 0.02 \\ 4000-4000 & 8.93 & 6.62 & 1.95 & 0.36 \\ 4500-5000 & 32.58 & 14.39 & 13.39 & 4.80 \\ 5000-5500 & 8.39 & - & 8.39 & - \\ 5500-6000 & 12.24 & - & 12.24 & - \\ 6000-6500 & 4.09 & - & 4.09 & - \\ >6500 & 1.77 & - & 1.77 & - \\ & & & & \\ \text { Totals } & 97.74 & 39.48 & 53.08 & 5.18\end{array}$

provides a visual display of the signal, and the timing can be read directly. The oscilloscope has been modified to accept an external $12 \mathrm{~V}$ d.c. power supply; the receiver antenna is identical to that used with the transmitter. No problems with radio-frequency interference were encountered; local ambient radio-frequency noise was not a problem because of the remoteness of the study area.

For the determination of ice thickness, the value for the radio-wave speed in ice is taken from Paterson (1981) to be $v_{\mathrm{i}}=168 \mathrm{~m} \mathrm{us}^{-1}$. To convert the time-amplitude scale into a depth scale, the following equation is used:

$$
d=\frac{\left(\left[\left(t+t_{0}\right) v_{\mathrm{j}}\right]^{2}-s^{2}\right)^{\frac{1}{2}}}{2}
$$

where $d$ is the ice thickness in $\mathrm{m}, t$ is the time in $\mu \mathrm{s}$ from arrival of air wave to arrival of secondary pulse, $t_{0}=s / v_{\mathrm{a}}$, where $v_{\mathrm{a}}$ is $300 \mathrm{~m} \mathrm{\mu s}^{-1}$ and is the speed of light in air, and $s$ is antenna spacing. The margin of error in the time measurement from the oscilloscope is about 0.2 divisions so, with $0.1 \mu \mathrm{s}$ per division, this represents about $20 \mathrm{~m}$ of ice. The sensitivity of the trigger setting is thought to introduce another error in the receiving unit of about 0.1 division, or $10 \mathrm{~m}$ of ice.

The uncertainty associated with a spatially sparse data set is an insidious problem throughout the Earth sciences. In this case, it is difficult to know from what direction the reflection is coming, and thus what part of the subglacial topography is actually being sampled.

\section{FIELD MEASUREMENTS}

\section{Depth sounding}

All measurements on Miar Glacier were made during June and July 1987. The antennae were spaced $80-100 \mathrm{~m}$ apart to avoid receiver saturation and were always placed perpendicular to the glacier-flow direction to minimize undesirable reflections from valley walls. Altogether, measurements were made at 18 surveyed points on the glacier in the region below the ice fall, and in the ogive field (Fig. 3). At 12 locations the reflections could be identified with confidence as being basal. The long-profile and transverse-profile measurements of glacier depth are shown in Figures 4 and 5.

\section{Survey data}

Figure 3 shows the locations of stakes monitored in 1986 and 1987 for flow studies. The map uses the 1939 Shipton survey (Mott, 1950) as a base and is improved, where possible, with data from the 1986 and 1987 surveys. All surveys were made from a point MM located about $70 \mathrm{~m}$ above the glacier surface and at a distance of about $400 \mathrm{~m}$ from the glacier. The instrument used was a Wild T2 theodolite equipped with a DI4 distomat. Accuracy for points surveyed was $5 \mathrm{~mm} \pm 5$ part per million. All points surveyed were within about $1.5 \mathrm{~km}$ of the survey point and maximum errors for point locations were thus about $15 \mathrm{~mm}$.

\section{ANALYSES}

The results of glacier-depth soundings are shown in Figures 4 and 5. The seven depths taken along the central axis of the glacier (Fig. 4) are consistent and fall mostly in the range $453-487 \mathrm{~m}$. The greater depth of $555 \mathrm{~m}$ at $\mathrm{M} 12$, is probably because this point is furthest towards the glacier right bank, and also because, as indicated in the transverse profile (Fig. 5), the deepest part of the glacier is slightly to the right of centre; it is also a reading which was subjectively rated poor, indicating concern over interpretation of the signal.

The crests of 20 successive ogives were surveyed along a line running down the approximate centre of the glacier. The mean distance between ogives on this line was $166 \mathrm{~m}$. Above the transverse profile, the mean distance apart was $143 \mathrm{~m}$ and the mean surface slope was $1.9^{\circ}$. It was always a subjective judgement as to what exactly constituted the crest of an ogive, so that quoted widths of individual ogives may well be inaccurate by up to $10 \mathrm{~m}$. However, by measuring the distances between many successive crests, average widths become more meaningful. If there is any consistent bias in these measurements it will have been towards slightly exaggerating the ogive spacing, as some slight deviations were taken from the centre line of the glacier.

Surface movement of the glacier was monitored during the summers of 1986 and 1987 on the transverse profiles shown in Figures 3 and 5. Table II summarizes these movement data. There are three points to note. First, the glacier is exhibiting blockschollen flow. Velocities increase rapidly from the edges of the glacier, and over most of its width the glacier is moving at a fairly constant velocity. Secondly, as shown in Table II, velocities during the summer can vary while, on the evidence from one stake only, summer and winter velocities are not markedly different. No attempt has yet been made to correlate these different velocities with availability of melt water. Thirdly, 


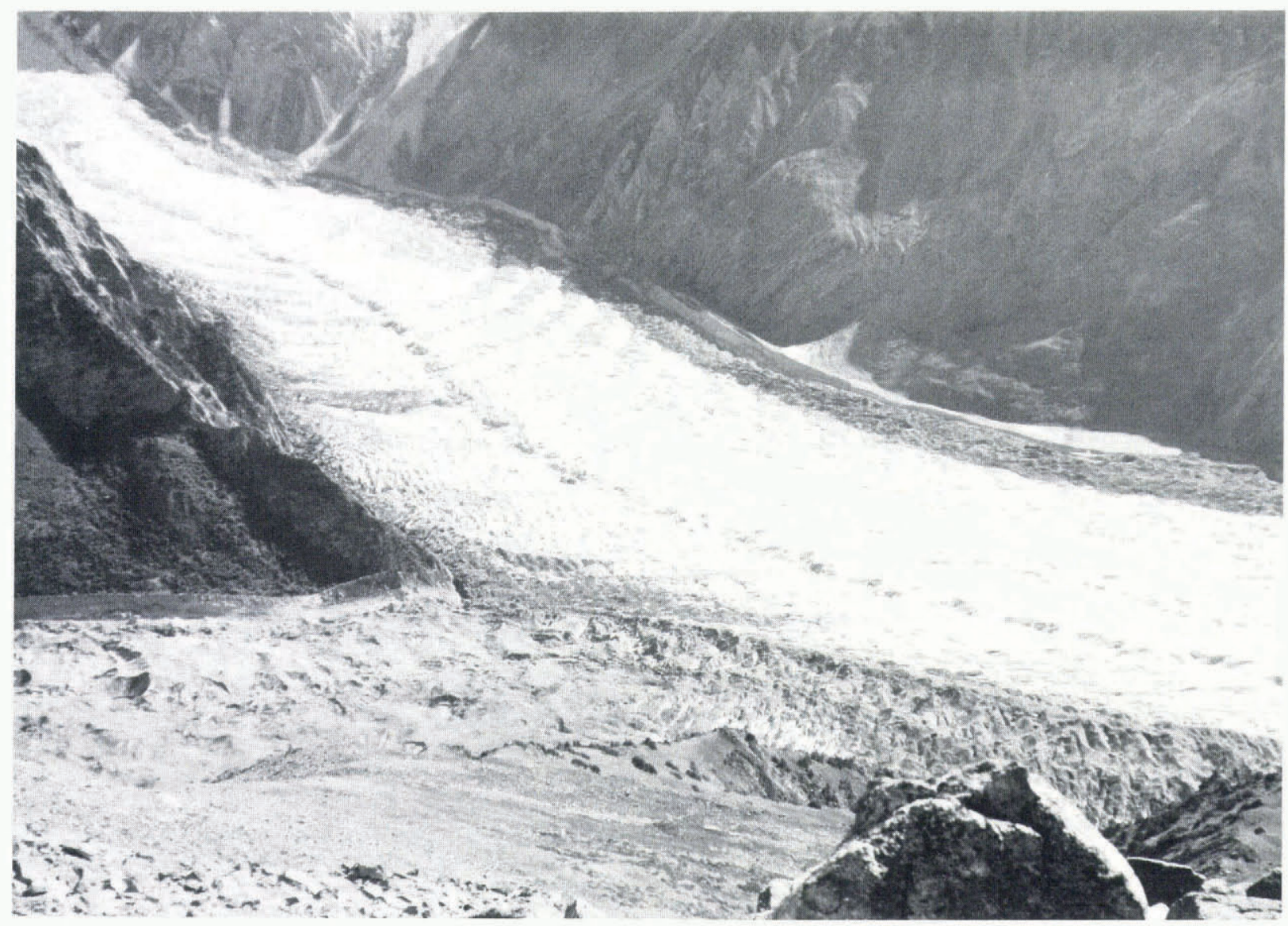

Fig. 2. Miar Glacier from Rosh Phari showing wave ogives (photograph by K. Hewitt).

annual surface movement at point M4, measured as $164.7 \mathrm{~m}$ between 14 May 1986 and 18 May 1987, is very similar both to the mean spacing of all 20 ogives of $166 \mathrm{~m}$, and also to the spacing of the two ogives nearest to M4 which was $158.5 \mathrm{~m}$. Using a distance-weighted average, the mean annual surface velocity is calculated as $148.5 \mathrm{~m} \mathrm{a}^{-1}$. Following Nye (1965), this is the figure taken as the mean annual velocity through the transverse section.

The base of the glacier shown in Figure 5 has been depicted as a series of straight lines joining adjacent depth soundings; no attempt has been made to fit a smooth curve through these points. The resulting cross-sectional area is $3.82 \times 10^{5} \mathrm{~m}^{2}$. Average ice flux through the section is calculated as the product of cross-sectional area and mean annual movement, and is $5.67 \times 10^{7} \mathrm{~m}^{3} \mathrm{a}^{-1}$, or $5.10 \times 10^{7} \mathrm{~m}^{3} \mathrm{a}^{-1}$ water equivalent.

\section{HYDROLOGICAL IMPLICATIONS}

Care must be taken in interpreting the figure of $5.10 \times 10^{7} \mathrm{~m}^{3} \mathrm{a}^{-1}$ water equivalent. It is only a first approximation of water loss from the glacier below the transverse profile and it does not therefore represent total annual water yield from the area below the profile. Ice loss will be augmented by precipitation falling on that part of the glacier as either rainfall or snowfall with subsequent melt. There are also other assumptions related to glacier dynamics and glacier/climate equilibrium. Velocities may not be the same each year; the glacier may speed up in particularly warm years and the flux of ice through a cross-section may be affected by the passage of a kinematic wave. It is known that Miar Glacier has been in recession in the past few decades and the quantity of ice loss represented by glacier thinning or retreat would be additional to that passing through the transverse profile. Lastly, ice loss must be subdivided into evaporation and melt-water formation. Evaporation rates have not been measured accurately for this glacier, but in such a hot dry environment they are certainly high. The area of Miar Glacier below the transverse profile is approximately $7 \mathrm{~km}^{2}$. If the ice flux through the profile is assumed to represent

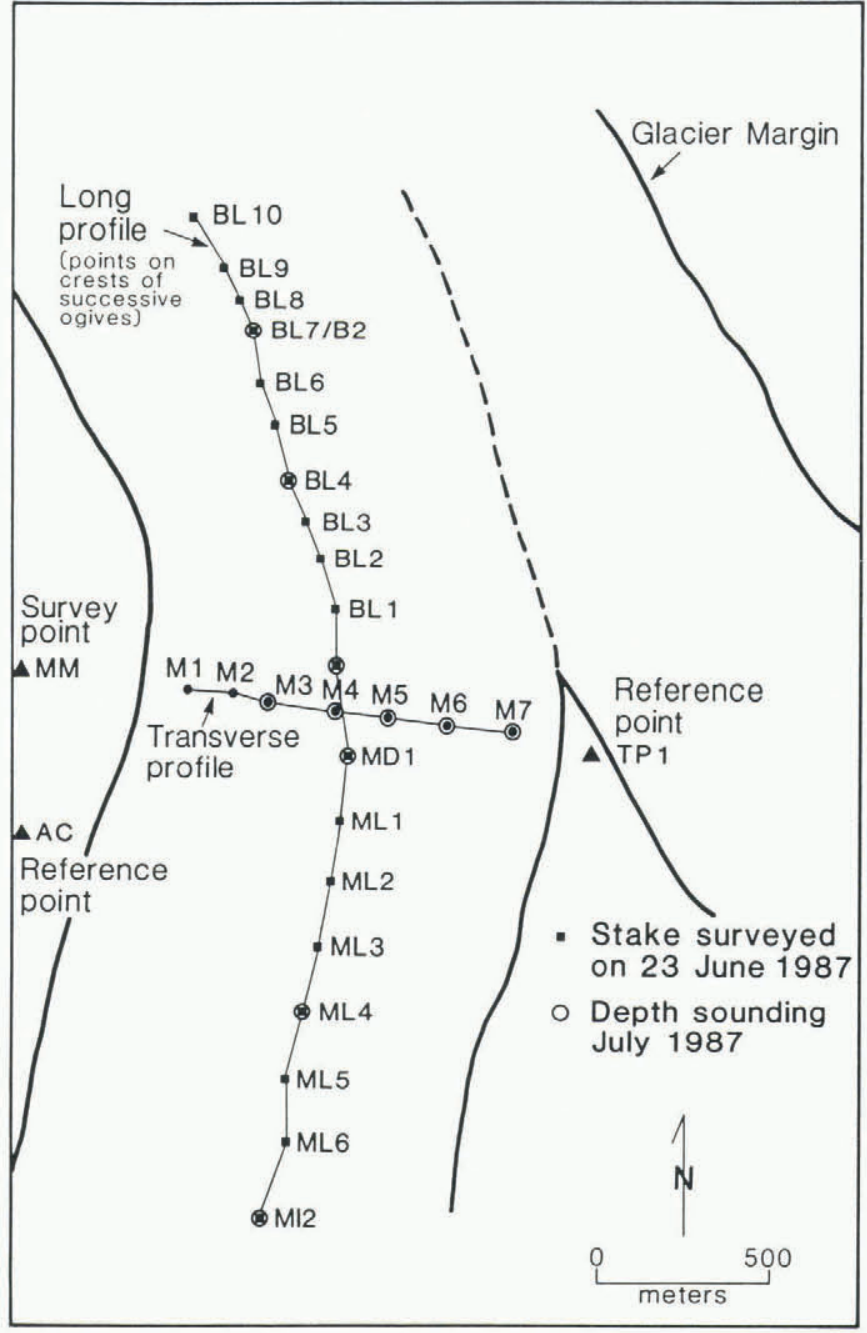

Fig. 3. Map of echo-sounding locations and positions of stakes surveyed for movement. 


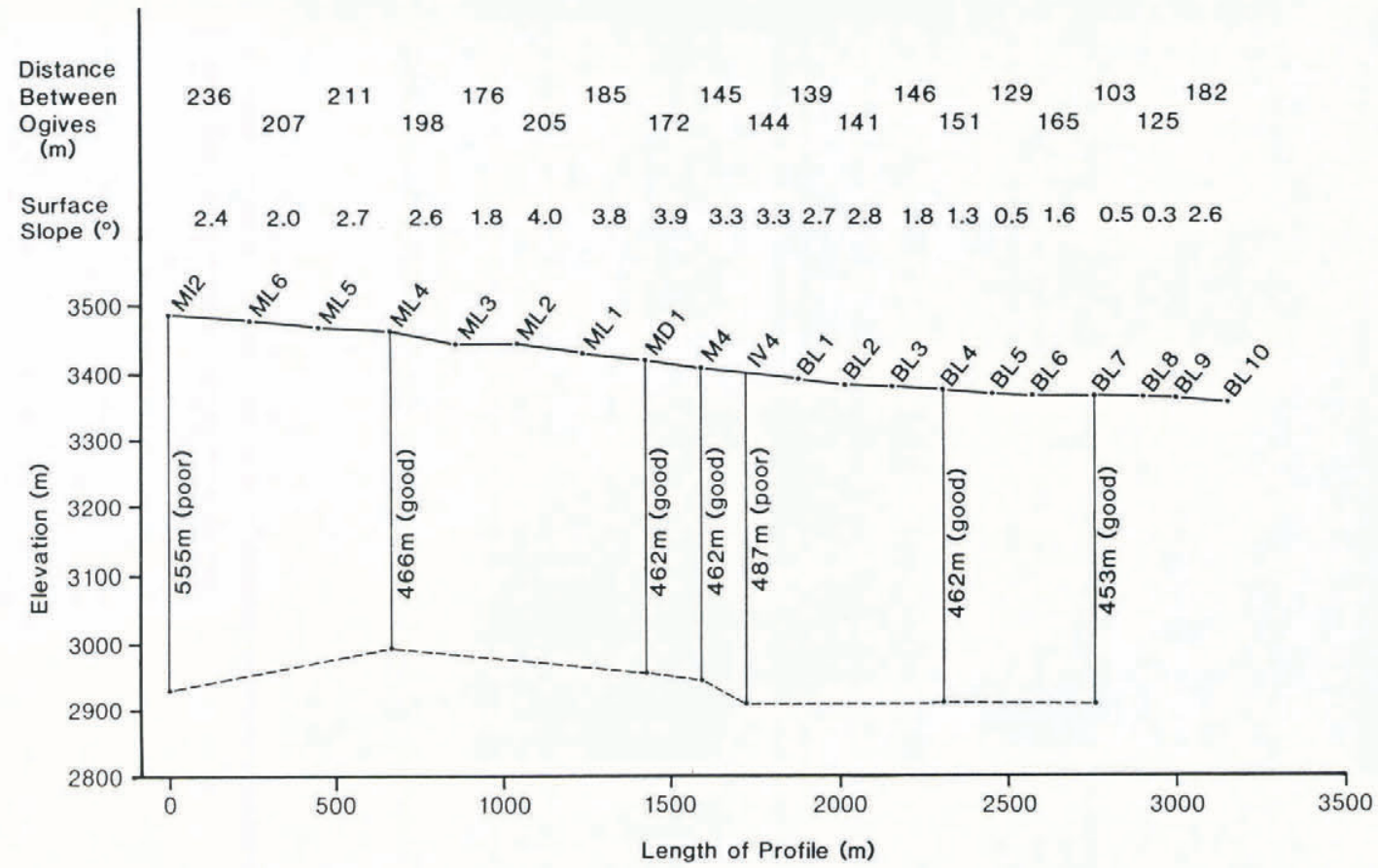

Fig. 4. Long profile from M12 to BL10.

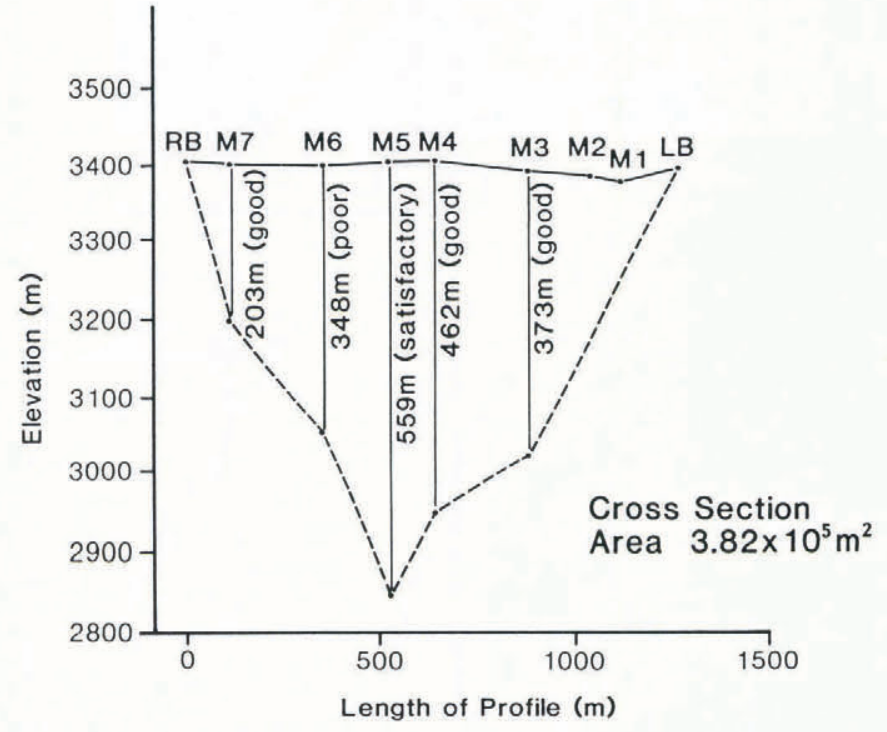

Fig. 5. Transverse profile M1 to M7. ice loss equally over this area, then mean ice loss producing run-off and evaporation, but discounting loss due to glacier thinning, is $8.10 \mathrm{~m} \mathrm{a}^{-1}$.

\section{FUTURE WORK}

It is intended that additional work be undertaken on Miar Glacier in the near future. This will consist of a more comprehensive study of glacier movement for all areas below the ice fall, and the establishment of a network of ablation stakes monitored throughout the summer melt season. Such measurements, tied in with climatic observations at local meteorological stations, are expected greatly to help in the interpretation of the 1987 findings. Mapping of the glacier ablation area at successive intervals in the future will also help in the estimation of ice loss due to glacier retreat.

It is hoped that this method of estimating water yield from the ablation areas of major glaciers in the Karakoram will be applied to a number of other glaciers in the same general region in order to make possible an estimate of the differences between glaciers.

TABLE II. SURFACE MOVEMENT ON TRANSVERSE PROFILE

Stake

$$
14 \text { May to }
$$

27 July 1986

Total

Daily movement movement

(m) $\quad(\mathrm{m} / \mathrm{d})$

$\begin{array}{lll}\text { M1 } & 31.7 & 0.43 \\ \text { M2 } & 36.8 & 0.50 \\ \text { M3 } & 39.8 & 0.54 \\ \text { M4 } & 41.6 & 0.56 \\ \text { M5 } & 42.4 & 0.57 \\ \text { M6 } & 42.5 & 0.57 \\ \text { M7 } & 39.4 & 0.53\end{array}$

27 July 1986

to 18 May 1987

Total Daily movement movement

$\begin{array}{cc}(\mathrm{m}) & (\mathrm{m} / \mathrm{d}) \\ - & - \\ - & - \\ \overline{-} & - \\ 123.1 & 0.42 \\ - & - \\ - & - \\ - & -\end{array}$

18 May to

23 June 1987

Total Daily movement movement

$\begin{array}{ll}(\mathrm{m}) & (\mathrm{m} / \mathrm{d}) \\ & \\ 15.9 & 0.44 \\ 18.1 & 0.50 \\ 19.0 & 0.53 \\ 20.0 & 0.56 \\ 20.5 & 0.57 \\ 20.7 & 0.57 \\ 19.8 & 0.55\end{array}$

23 June to 15 August 1987

Total Daily movement movement

$\begin{array}{ll}(\mathrm{m}) & (\mathrm{m} / \mathrm{d}) \\ & \\ 18.1 & 0.34 \\ 21.0 & 0.40 \\ 21.5 & 0.41 \\ 23.3 & 0.44 \\ 23.6 & 0.45 \\ 24.3 & 0.46 \\ 23.3 & 0.44\end{array}$




\section{ACKNOWLEDGEMENTS}

This work was carried out as part of the work of the Snow and Ice Hydrology Project, jointly funded by the Water and Power Development Authority in Pakistan and the International Development Research Centre in Canada. Funding support from these organizations is gratefully acknowledged.

\section{REFERENCES}

Clarke, G.K.C. Unpublished. Operating manual for $1-5 \mathrm{MHz}$ monopulse radar. University of British Columbia. Department of Geophysics and Astronomy.

Hewitt, K. 1985. Snow and ice hydrology in remote, high mountain areas: the Himalayan sources of the river Indus. Waterloo, Ontario, Wilf rid Laurier University. (Snow and Ice Hydrology Project. Working Paper 1.)

Hewitt, K., ed. 1986. Snow and Ice Hydrology Project - Annual Report and Scientific Papers, 1985. Waterloo, Ontario, Wilf rid Laurier University.

Hewitt, K., ed. 1987. Snow and Ice Hydrology Project
- Annual Report 1986. Waterloo, Ontario, Wilfrid Laurier University.

Mott, P.G. 1950. Karakoram Survey, 1939. A new map. Geogr. J., 116(1-3), 89-95.

Nye, J.F. 1965. The flow of a glacier in a channel of rectangular, elliptic or parabolic cross-section. J. Glaciol., 5(41), 661-690.

Paterson, W.S.B. 1981. The physics of glaciers. Second edition. Oxford, etc., Pergamon Press.

Reid, I.A. and W.S.B. Paterson. 1973. Simple method of measuring the average amount of water produced annually by melting of ice on a glacier. International Association of Scientific Hydrology Publication 95 (Symposium at Cambridge 1969 - Hydrology of Glaciers), 215-218.

Rose, G.C. and R.S. Vickers. 1974. Calculated and experimental response of resistively loaded $\mathrm{V}$ antennas to impulsive exitation. Int. J. Electron., 37, 261-271.

Watts, R.D. and A.W. England. 1976. Radio-echo sounding of temperate glaciers: ice properties and sounder design criteria. J. Glaciol., 17(75), 39-48.

Watts, R.D. and D.L. Wright. 1981. Systems for measuring thickness of temperate and polar ice from the ground or from the air. J. Glaciol., 27(97), 459-469. 